\title{
A Comparative Study on Anti-diabetic Effects of Aqueous Trigonella foenum graecum, Hibiscus cannabinus Linn, and Cicer arietinum extracts on Alloxan Induced Diabetic Male Albino Rats
}

\author{
Kailash S. Chadchan', Swastika N. Das*, Jameel G. Jargar², Kusal K. Das ${ }^{3}$ \\ 'Department of Chemistry, B.L.D.E.A's College of Engineering and Technology, Vijayapur -586103, (Affiliated to Visvesvaraya Technological University, Belagavi) Karna- \\ taka, INDIA. \\ 2Department of Physiology, Al Ameen Medical College, Vijayapur, Karnataka, INDIA. \\ 3Department of Physiology, Shri B.M. Patil Medical College, Hospital and Research Centre, BLDE University, Vijayapur -586103, Karnataka, INDIA.
}

\begin{abstract}
Objective: To compare anti-diabetic effect between the different aqueous extracts of green leafy plants locally available in North Karnataka region of India on alloxan induced diabetic male albino rats. Materials and Methods: The preparation of aqueous extracts, preliminary phytochemical analysis and toxicity screening test of 3 aqueous extracts was done by using standard protocol. To study anti-diabetic activity experimental rats were divided into five groups viz. Group I (Control), Group II (Diabetic, Alloxan monohydrate, $15 \mathrm{mg} / 100 \mathrm{~g}$ bwt, i.p.), Group III (Diabetic with Trigonella foenum graecum), Group IV (Diabetic with Hibiscus cannabinus Linn) and Group V (Diabetic with Cicer arietinum). All above extracts were supplemented with same dose i.e. $12.5 \mathrm{mg} / 100 \mathrm{~g}$ bwt, orally. The blood glucose levels were evaluated in all the above experimental groups after acute (OGTT) and sub chronic (2 weeks) supplementation. Results: Our results depicts statistically significant decreased blood glucose level in Group III rats after both acute and sub chronic supplementation whereas in Group IV rats only after sub chronic supplementation when compared with Group II rats. But, Group V rats
\end{abstract}

not showed any significant change in both acute as well as sub chronic exposure when compared with Group II rats. Conclusion: Trigonella foenum graecum and Hibiscus cannabinus Linn. leaves may be used as a dietary supplement in diabetic patients.

Key words: Trigonella foenum graecum, Hibiscus cannabinus Linn., Cicer arietinum

Key message: Aqueous Trigonella foenum graecum leaves extract can be used as a dietary supplement for controlling blood glucose level.

Correspondence :

Dr. Swastika N. Das, Professor of Chemistry, B.L.D.E.A's College of Engineering and Technology, Vijayapur-586103, Karnataka, INDIA.

Tel: 07022123354

Email: drswastika@yahoo.com

DOI: 10.5530/jyp.2017.9.45

\section{INTRODUCTION}

Trigonella foenum graecum (Methi), Hibiscus cannabinus Linn. (Pundi) and Cicer arietinum (Channa) leaves are usually consumed by the people as a dietary supplement and available locally in North Karnataka of India. Trigonella foenum graecum leaves is available throughout the year, whereas, Hibiscus cannabinus Linn. and Cicer arietinum leaves are seasonal, which are available only during the months of November to March. There are many Medicinal plants of India which are known to have anti-diabetic potential. ${ }^{1}$ Similarly plants like Nerium indicum possess antidiabetic activity ${ }^{2}$. Hibiscus cannabinus Linn. and Trigonella foenum graecum leaves which are commonly used as a dietary supplement also known to possess anti-diabetic activities ${ }^{3}$ while that of Cicer arietinum leaves remains unknown. The synthetic drugs which are used to control diabetes mellitus have many side effects; hence, replacement of these drugs by plant based alternatives is essential. Many herbal medicines possess anti-diabetic properties. ${ }^{3}$ Hence, the present work is carried out to compare anti-diabetic effect between the different aqueous extracts of Trigonella foenum graecum, Hibiscus cannabinus Linn. and Cicer arietinum leaves on alloxan induced diabetic male albino rats exposed to both acute and sub chronic supplementation.

\section{MATERIALS AND METHODS}

\section{Collection and Identification of Plants}

The fresh Trigonella foenum graecum, Hibiscus cannabinus Linn. and Cicer arietinum leaves were collected from the local market and were authenticated ${ }^{4}$ by Dr. M. B. Mulimani, Associate Professor, Department of Botany, BLDEA's S. B. Arts and K. C. P. Science College, Vijayapur, Karnataka, India.

\section{Preparation of Plant Extracts}

The $5 \mathrm{~g}$ of fresh leaves were washed thoroughly with distilled water, crushed and extracted with $100 \mathrm{~mL}$ distilled water at $50-60^{\circ} \mathrm{C}$ temperature for $1 \mathrm{hr}$. The resulting extract was filtered using Whatmann filter paper no. 1. Filtrate is used as an aqueous plant extracts and orally fed to the rats. The extracts of all the plants were prepared with similar protocol.

\section{Phytochemical analysis}

Preliminary phytochemical analysis of freshly prepared plant extracts was carried out to identify the phyto constituents using standard procedures. ${ }^{5}$

\section{Animals}

Adult male albino rats of Wistar strain (Rattus norvegicus) weighing 180-200g were housed in central animal house of BLDE University's Shri. B. M. Patil Medical College, Hospital and Research Centre, Vijayapur with $12 \mathrm{hr}$ light: $12 \mathrm{hr}$ dark cycle. The rats were divided into five groups 
of six rats each. Three rats were kept in each metabolic wire cage $(60 \mathrm{~cm} \mathrm{x}$ $30 \mathrm{~cm} \times 20 \mathrm{~cm})$. Standard pellets obtained from Hindustan lever rat feed, Mumbai, India, were used as a basal diet during the experimental period. The control and experimental rats were provided food and drinking water ad libitum.

\section{Chemicals}

The chemicals used during the experiment are alloxan monohydrate (Spectrochem Pvt. Ltd., Mumbai), Tween 80 (S.D. Fine-chem limited, Mumbai). Accu-chek Active Glucometer, Roche Diagnostic Corporation, Germany, Blood gluco-strips (Roche Diagnostic Pvt. Ltd., Mumbai, India). All other chemicals and reagents used were of analytical grade.

\section{Acute oral toxicity studies of extract}

The acute oral toxicity studies of extracts were carried out as per the OECD guidelines, draft guidelines $423 .{ }^{6}$ Administration of the stepwise doses of aqueous extracts of leaves from $5 \mathrm{mg} / 100 \mathrm{~g}$ b.wt up to a dose of $125 \mathrm{mg} / 100 \mathrm{~g}$ b.wt caused no significant signs of toxicity in the tested rats. One-tenth of the upper limit dose was selected for the examination of anti-diabetic activity.

\section{Experimental Groups}

The experimental rats were divided into five groups of six rats each as shown in table 1.

\section{Induction of diabetes}

The overnight fasted rats were induced for diabetes with a single intra peritoneal injection (i.p.) of $15 \%$ freshly prepared alloxan monohydrate solution $(15 \mathrm{mg} / 100 \mathrm{~g}$ b.wt) in sterile normal saline just before use. Since alloxan is capable of producing fatal hypoglycemia due to massive pancreatic insulin release, rats were treated with $20 \%$ glucose solution (i.p.) after $6 \mathrm{hr}$. The rats were then kept on 5\% glucose solution for $24 \mathrm{hrs}$ to prevent hypoglycemia. After three days, blood samples were collected from the tail vein. Serum was separated and fasting glucose levels were estimated by glucose oxidase-peroxidase enzymatic method to confirm diabetes. ${ }^{7}$ Only the rats which have shown hyperglycemia (glucose level $>250 \mathrm{mg} / \mathrm{dL}$ ) were selected for the study.

\section{Oral glucose tolerance test (OGTT)}

Fasting blood sugar level (FBS) was measured in the rats of all groups. After 30min of leaves extract administration, the rats of all five groups were orally treated with $0.35 \mathrm{mg} / 100 \mathrm{~g}$ b.wt. of glucose. Blood samples were collected from the rat tail vein just prior to glucose administration (0.0hr) and at $0.5 \mathrm{hr}, 1.0 \mathrm{hr}, 1.5 \mathrm{hr}$ and $2.0 \mathrm{hr}$ after glucose loading. Blood glucose levels were measured immediately by using glucometer.

\section{Determination of blood glucose level}

After the day of OGTT, administration of extracts $(12.5 \mathrm{mg} / 100 \mathrm{~g}$ b. wt, orally) was continued every day in designed experimental groups (group III, group IV and group V) till 13 days. Blood sample was collected from the rat tail vein after 30 minutes of ingestion of plant extracts on $1^{\text {st }}, 3^{\text {rd }}$, $5^{\text {th }}, 7^{\text {th }}, 9^{\text {th }}, 11^{\text {th }}, 13^{\text {th }}$ day in the rats of all groups. Blood glucose levels were measured by using glucometer.

\section{Statistical analysis}

The statistical data, obtained from all the control and experimental samples analyzed for evaluating the range of significance. Results expressed as mean \pm SD values were calculated for each group. To determine the significance of inter-group differences, one way analysis (ANOVA) followed by 'post hoc $t$ test' were done.

\section{Ethics}

All the animal experiments were conducted according to the ethical norms approved by CPCSEA, Ministry of Social Justice and Empowerment, Government of India, and ethical clearance was granted by Institutional Animal Ethical Committee, BLDE University, Vijayapur.

\section{RESULTS}

\section{Phytochemical analysis}

The preliminary phytochemical analysis of aqueous extract of Trigonella foenum graecum leaves confirms the presence of flavonoids, saponins, triterpenes and steroids. Similarly, the preliminary phytochemical analysis of aqueous extract of Hibiscus cannabinus Linn. leaves showed the presence of flavonoids, saponins, triterpenes and Tannins. Whereas, the preliminary phytochemical analysis of aqueous extract of Cicer arietinum leaves revealed the presence of flavonoids, saponins and triterpenes (Table 2).

\section{Acute oral toxicity studies}

In acute toxicity study, aqueous extracts of leaves showed non-significant toxicity sign when observed for the parameters during the first $4 \mathrm{hrs}$ and followed by daily observations for 14 days and mortality was also not observed; the drugs were found to be safe at the tested dose level of $125 \mathrm{mg} / 100 \mathrm{~g}$ b. wt. One-tenth of this dose level was taken as effective dose. All the extracts were experimented at the same dose of $12.5 \mathrm{mg} / 100 \mathrm{~g} \mathrm{~b}$. wt. In order to ascertain a scientific base for the usefulness of these plants in the treatment of diabetes, it was decided to evaluate experimental design of antidiabetic activity by following glucose tolerance test.

\section{Oral glucose tolerance test}

Group I rats showed the typical normal OGTT response i.e, glucose level increased at $1.0 \mathrm{hr}$ and decreased to base line after $2.0 \mathrm{hr}$ of glucose treatment. In group II diabetic rats, the glucose level kept on increasing till $1.0 \mathrm{hr}$ of the glucose treatment with slight decrease at 2.0hr. The Group III rats which are treated with Trigonella foenum graecum leaves extract have shown significant decrease in the glucose level, less than the fasting blood glucose level after $2.0 \mathrm{hr}$ of the glucose treatment. The group IV and group $\mathrm{V}$ diabetic rats which are treated with Hibiscus cannabinus Linn. and Cicer arietinium extracts respectively did not show any positive response even after $2.0 \mathrm{hr}$ of the glucose supplementation (Figure 1).

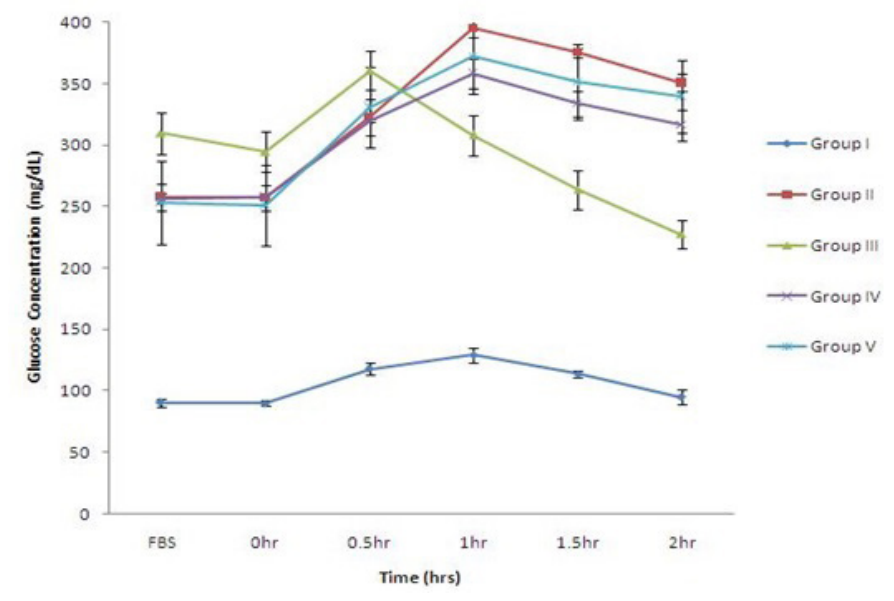

Figure 1: Effect of acute exposure of T. graecum, H. cannabinus Linn and C. arietinum Linn. leaves extract on blood glucose level in diabetic rats. 


\section{Sub chronic effects (13 days) of leaves extracts and glucose level}

The concentration of glucose in Group I normal control rats remained constant till the $13^{\text {th }}$ day. Group II diabetic rats showed progressive rise of blood glucose concentration till $13^{\text {th }}$ day. Group III diabetic rats which are treated with Trigonella foenum graecum extract showed a significant decrease in blood glucose level. Similarly, Group IV diabetic rats which are treated with Hibiscus cannabinus Linn. extract also showed a significant decrease in blood glucose level. Whereas, Group V rats which are treated with Cicer arietinum leaves extract did not show any positive response (Figure 2).

\section{DISCUSSION}

It can be depicted from the observations of OGTT results (Figure. 1), that aqueous extract of Trigonella foenum graecum leaves reduced greater glucose concentration, where as Hibiscus cannabinus Linn. and Cicer arietinum did not show any positive response. The results of sub chronic exposure of plant extracts were quite interesting. Trigonella foenum graecum leaves extract showed a significant decrease in the blood glucose level after 13 days treatment. Interestingly, Hibiscus cannabinus Linn. which did not show any positive response during OGTT, showed a significant decrease in the blood glucose level on sub chronic exposure indicating anti diabetic potential on prolonged treatment. However, the percentage reduction in the blood glucose level is less than that treated with Trigonella foenum graecum extract (Figure 3). It was reported that the chemical components such as flavonoids, saponins and triterpenes are beneficial to control diabetes. ${ }^{8}$ The preliminary Pytochemical analysis of Trigonella foenum graecum and Hibiscus cannabinus Linn leaves confirms the presence of these components. The flavanoids play a major role in maintaining blood glucose levels, glucose uptake, insulin secretion and modulating immune function to prevent specific diabetes mellitus. ${ }^{9}$

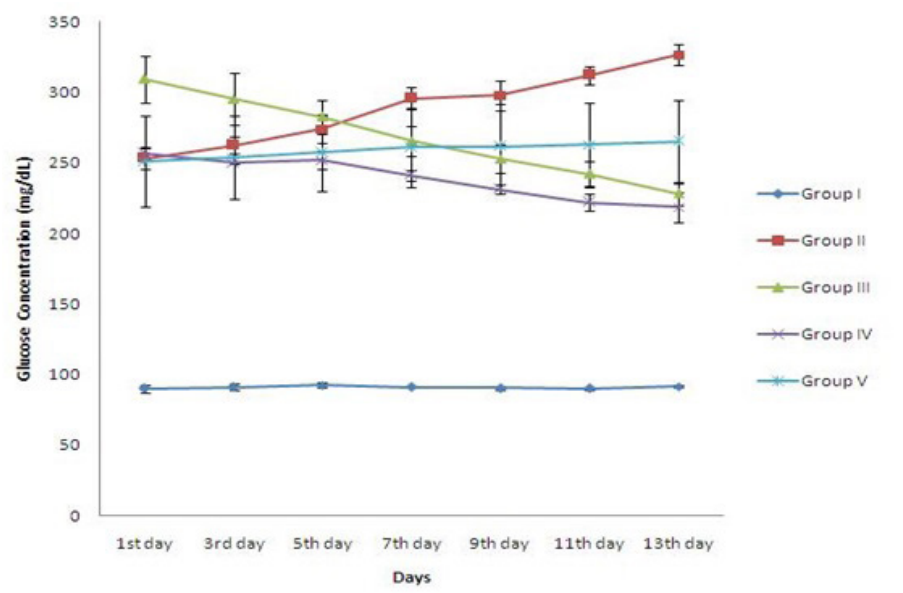

Table 1: The experimental rats were divided into following groups

\begin{tabular}{|c|c|}
\hline Group I & Normal control \\
\hline Group II & Diabetic control \\
\hline Group III & $\begin{array}{l}\text { Diabetic rats are treated with Trigonella foenum graecum } \\
\text { extract }(12.5 \mathrm{mg} / 100 \mathrm{~g} \text {, orally) }\end{array}$ \\
\hline Group IV & $\begin{array}{l}\text { Diabetic rats are treated with Hibiscus cannabinus Linn } \\
\text { extract }(12.5 \mathrm{mg} / 100 \mathrm{~g} \text {, orally })\end{array}$ \\
\hline Group V & $\begin{array}{l}\text { Diabetic rats are treated with Cicer arietinum extract } \\
\qquad(12.5 \mathrm{mg} / 100 \mathrm{~g} \text {, orally })\end{array}$ \\
\hline
\end{tabular}

Figure 2: Effect of sub chronic exposure of T. graecum, H. cannabinus Linn and C. arietinum Linn. leaves extract on blood glucose level in diabetic rats.

\begin{tabular}{|c|c|c|c|c|c|}
\hline SI.No. & $\begin{array}{l}\text { Phytochemical } \\
\text { Constituents }\end{array}$ & Name of the test & $\begin{array}{l}\text { Trigonella } \\
\text { foenum } \\
\text { graecum }\end{array}$ & $\begin{array}{l}\text { Hibiscus. } \\
\text { Cannabinus } \\
\text { Linn. }\end{array}$ & $\begin{array}{c}\text { Cicer } \\
\text { arietinum }\end{array}$ \\
\hline \multirow{3}{*}{1.} & \multirow{3}{*}{ Alkaloids } & Mayer's test, & - & - & - \\
\hline & & Dragondorff's test, & - & - & - \\
\hline & & Wager's test & - & - & - \\
\hline \multirow{3}{*}{2.} & \multirow{3}{*}{ Carbohydrates } & Molish's test & - & - & - \\
\hline & & Fehling's test & - & - & - \\
\hline & & Benedict's test & - & - & - \\
\hline \multirow{2}{*}{3.} & \multirow{2}{*}{ Flavonoids } & Lead acetate test & + & + & + \\
\hline & & Mineral acid test & + & + & + \\
\hline 4. & Saponins & Libarmann Burchard test & + & + & + \\
\hline \multirow{2}{*}{5.} & \multirow{2}{*}{ Tannins } & Gelatin test & - & + & - \\
\hline & & Ferric chloride test & - & + & - \\
\hline \multirow[t]{2}{*}{6.} & \multirow[t]{2}{*}{ Triterpenes } & $\begin{array}{l}\text { Libermann storch } \\
\text { Morawski test }\end{array}$ & + & + & + \\
\hline & & Salkowski's test & + & + & + \\
\hline 7. & Steroids & $\begin{array}{l}\text { Libermann Burchard sterol } \\
\text { reaction }\end{array}$ & + & - & - \\
\hline \multirow{2}{*}{8.} & \multirow{2}{*}{ Caretenoids } & Antimony trichloride & - & - & - \\
\hline & & Conc. $\mathrm{HCl}$ with phenol & - & - & - \\
\hline
\end{tabular}




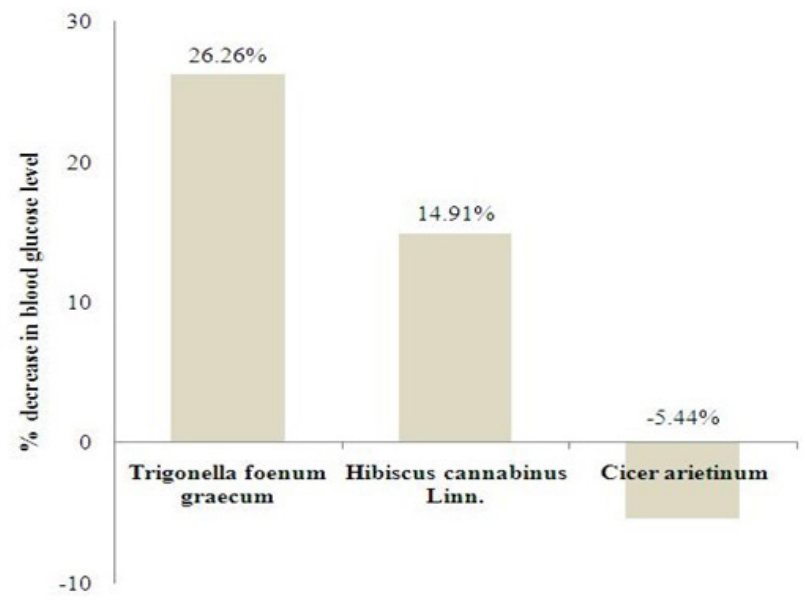

Figure 3: \% decrease in blood glucose level on sub chronic exposure of plant extracts in male diabetic rats.

The consumption of flavanoids or flavanoid rich foods reduces the risk of diabetes mellitus. On the other hand, Saponins have the ability to reduce increased plasma blood glucose, hence, making it useful in treating diabetes mellitus. The hypoglycaemic effect of saponin is through restoration of insulin response, improvement in insulin signalling, increase plasma insulin and induction of insulin release from the pancreas. ${ }^{10}$ Similarly, the presence of Triterpenes inhibit enzymes involved in glucose metabolism and prevent the development of insulin resistance thus normalising insulin levels. ${ }^{11}$ However, the preliminary phytochemical analysis of Cicer arietinum leaves confirms the presence of flavonoids, saponins and triterpenes but it did not show any antidiabetic activities, probably because the bio active component responsible for hypoglycaemic activities might not be present in the leaves extract.

\section{CONCLUSION}

The acute and sub chronic exposure results obtained from this study reveal that Trigonella foenum graecum leaves has significant anti-diabetic potential. The Trigonella foenum graecum leaves may be used as a substitute for synthetic drugs to treat diabetic patients. On prolonged treatment with Hibiscus cannabinus Linn. leaves extract showed reduction in the blood glucose level, it can also be used as a anti-diabetic drug with lesser potential. Whereas, the Cicer arietinum leaves extract, which did not show any positive results, cannot be used as an anti-diabetic drug.

\section{ACKNOWLEDGEMENT}

Authors deeply acknowledge the technical help from Dr. C. C. Simpi and Shri. Managond of BLDEA's College of Pharmacy, Vijayapur. Authors also acknowledge the financial support from the BLDEA's V. P. Dr. P. G. Halakatti College of Engineering and Technology, Vijayapur, Karnataka.

\section{CONFLICT OF INTEREST}

There is no conflict of Interest.

\section{ABBREVIATION USED}

T. graecum: Trigonella foenum graecum; H. cannabinus: Hibiscus cannabinus Linn.; C. arietinum: Cicer arietinum Linn.

\section{REFERENCES}

1. Grover JK, Yadav S, Vats V. Medicinal plants of India with anti-diabetic potential. J Ethnopharmacol. 2002; 81(1):81-100.

2. Sikarwar MS, Patil MB, Kokate CK, Sharma S, Bhat V. Antidiabetic Activity of Nerium indicum Leaf Extract in Alloxan induced Diabetic rats. Journal of Young Pharmacists. 2009; 1(4):340-345

3. Raj Kumar T, Udhayakumar E, Sekar M, Senthil Kumar MK. Antidiabetic activity of methanolic extract of Hibiscus cannabinus in streptozotocin induced diabetic rats. Intl J Pharma Biosci. 2011;2(1):125-30.

4. Rajasab AH, Mahamad Isaq. Documentation of folk knowledge on edible wild plants of North Karnataka. Indian J Trad Know. 2004;3:419-29.

5. Kumar D, Kumar S, Singh J, Narender, Rashmi, Vashistha B, Singh N. Free Radical Scavenging and Analgesic Activities of Cucumis sativus L. Fruit Extract. JYoung Pharm. 2010;2:365-8.

6. Parasuraman S. Toxicological screening. J Pharmacol Pharmacother. 2011 Apr-Jun; 2(2): 74-79

7. Kirana H, Srinivasan BP. Aqueous Extract of Garcinia Indica Choisy Restores Glutathione in Type 2 Diabetic Rats. J Young Pharm. 2010; 2(3): 265-268.

8. Trinder P. Determination of blood glucose using an oxidase-peroxidase system with a non-carcinogenic chromogen. J Clin Pathol. 1969;22:158-61.

9. Soumyanath A. Traditional Medicines for Modern Times: Antidiabetic plants, Taylor and Francis, 2005.

10. Vinayagam $R, X u$ B. Antidiabetic properties of dietary flavonoids: a cellular mechanism review. Nutr metab. 2015;12(1):1.

11. Olalekan O, Saponins E. Anti-diabetic principles from medicinal plants- A review. J Pathophysiol. 2015;22(2):95-103

12. Nazaruk J, Borzym-Kluczyk M. The role of triterpenes in the management of diabetes mellitus and its complications. Phytochem Rev. 2015;14(4):675-90.

Article History: Submission Date: 28-05-16; Received Date: 30-07-16; Acceptance Date: 21-08-16.

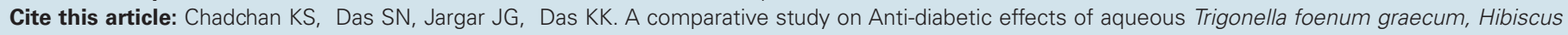
cannabinus Linn, and Cicer arietinum extracts on Alloxan induced Diabetic Male Albino Rats. J Young Pharm. 2017;9(2):230-3. 